\title{
Self-reported racial discrimination, response to unfair treatment, and coronary calcification in asymptomatic adults - the North Texas Healthy Heart study
}

\author{
Roberto Cardarelli*+1, Kathryn M Cardarelli², Kimberly G Fulda' , Anna Espinoza' ', Clifton Cage1, \\ Jamboor Vishwanatha ${ }^{3}$, Richard Young ${ }^{4}$, Darryl N Steele 5 and Joan Carroll 3
}

\begin{abstract}
Background: Accruing evidence supports the hypothesis that psychosocial factors are related to cardiovascular disease. However, a limited number of studies have investigated the pathophysiologic pathways through which these associations occur. The purpose of this study was to assess whether experiences of self-reported racial discrimination and reactions to unfair treatment were associated with coronary artery calcification (CAC), an indicator of subclinical coronary heart disease (CHD).

Methods: This cross-sectional study recruited 571 subjects (45 years and older) who were asymptomatic of CHD from Fort Worth, Texas from 2006 to 2008. Subjects completed a questionnaire, a multi-slice computed tomography scan to assess for CAC presence (measured as Agatston score $>0$ ), and serum chemistries. Logistic regression was used to estimate odds ratios (ORs) and 95\% confidence intervals ( $\mathrm{Cls}$ ) for the association between self-reported discrimination and CAC. Results were stratified by response to unfair treatment as it was found to significantly modify the relationship between discrimination and CAC.
\end{abstract}

Results: Among those who passively responded to unfair treatment, the odds of having CAC present were approximately 3 times higher for those experiencing discrimination $(\mathrm{OR}, 2.95 ; 95 \% \mathrm{Cl}, 1.19-7.32)$ after adjusting for age, gender, race/ethnicity, education, body mass index, hyperlipidemia, smoking status, hypertension, diabetes, and first degree relative with heart disease.

Conclusions: This is the first multi-racial/ethnic study to find racial discrimination associated with CAC, which differs based on how one responds to unfair treatment.

\section{Background}

Cardiovascular disease (CVD) remains the leading cause of death among adults and affects over 70 million people in the United States[1]. Despite marked declines in overall prevalence of CVD, racial and ethnic disparities in CVD prevalence exist[1-3]. Increasing evidence suggests that psychosocial factors may play a role in the development of CVD [4], although this is still debated[5]. Psycho-

* Correspondence: rcardare@hsc.unt.edu

1 Department of Family Medicine, Primary Care Research Institute, Texas College of Osteopathic Medicine, University of North Texas Health Science

Center, 3500 Camp Bowie Blvd, Fort Worth, TX, 76107, USA

+ Contributed equally

Full list of author information is available at the end of the article social factors including stress, depression, anger, anxiety, and lack of social support have been linked to CVD[4,6].

Racial discrimination is gaining attention as an independent factor for CVD. Conceptually defined as a source of acute and lifelong chronic stress [7-10], discrimination may contribute to CVD, indirectly by negatively impacting mental health $[11,12]$, inducing unhealthy behavior [13], or more directly [14], by inducing inflammation and platelet aggregation, which is an underlying pathophysiologic mechanism of atherosclerosis[15]. Internalizing unfair treatment rather than talking to others about the experience may further reinforce such stress[9,16,17]. The relationship between racial discrimination and 
hypertension has been the focus of prior investigations, for which the results have been equivocal[18-20]. However, investigations of racial discrimination and subclinical CVD are limited[21,22].

Recent advances in computed tomography (CT) scanning have allowed for the measurement of coronary artery calcification $(\mathrm{CAC})$, which may assist in detecting subclinical CVD by assessing the extent of atherosclerosis[23]. CAC is a noninvasive measure of subclinical atherosclerotic plaque calcification of the coronary arteries [23] and has been shown to independently predict coronary heart disease $[6,24]$ and coronary events in all racial/ ethnic groups[25,26]. The presence of CAC has also demonstrated variable ability to detect clinically apparent coronary artery disease[27].

A study of 181 African-American women revealed that higher levels of CAC were associated with chronic exposure to discrimination[28]. Investigators reported that for every unit increase in experiencing discrimination, there was a 2.8 fold increase in the odds of having coronary calcification. However, the study sample was limited to middle-aged women, and the measure of discrimination was not specific to racial discrimination. Available literature indicates that this study provided one of the few previous examinations of discrimination as an independent factor for CAC. Our study examined the relationship between self-reported racial discrimination, reaction to unfair treatment and CAC in a population of 571 asymptomatic adults. We hypothesized that discrimination would be associated with higher prevalence of coronary calcification and that individuals who internalized experiences of unfair treatment (i.e., passive response) would also have a higher prevalence of CAC compared to those who talked to others about such experiences (i.e, active response). To our knowledge, this represents the first study to examine these associations in a population of male and female individuals of multiple racial/ethnic groups.

\section{Methods}

\section{Study population}

The North Texas Healthy Heart (NTHH) study is a crosssectional study involving a convenience sample of 571 non-Hispanic whites, non-Hispanic African Americans, and Hispanics/Latinos recruited from 12 participating sites of the North Texas Primary Care Practice-Based Research Network (NorTex) from April 2006 to May 2008. NorTex is a collaborative network of primary care clinics serving low-income, under-represented populations of the Dallas/Fort Worth, Texas metropolitan area. The 12 family medicine/internal medicine clinic sites that participated in the NTHH study included 4 academic community-based clinics, 3 community health centers, 4 solo-practitioner private practices, and 1 federally-qualified health center. Participants were eligible for the study if they were over the age of 44, self-identified as non-Hispanic white, non-Hispanic African American, or Hispanic/Latino, and had no history of self-reported cardiovascular disease (coronary artery disease, peripheral arterial disease, history of myocardial infarction or stroke, or congestive heart failure), renal failure, or liver failure. All participants were screened for eligibility either on-site or via phone from a centralized NorTex research office located within the University of North Texas Health Science Center, Department of Family Medicine. Initial contact was made with 1,062 individuals, with 860 meeting eligibility criteria. Of those who were eligible, 670 were invited to participant and 571 agreed to participate and the remaining were wait-listed, representing an $85 \%$ recruitment rate (Figure 1). All study procedures were approved by the University of North Texas Health Science Center and JPS Health Network Institutional Review Boards.

\section{Study procedures}

All consented participants underwent a 1-hour face-toface interview in a single private temperature-controlled room. Women, except for those with a history of hysterectomy, underwent a urine pregnancy test, as pregnancy is a contraindication to computed tomography scanning. There were no positive urine pregnancy tests among the study participants. Participants then completed weight, height, waist/hip circumferences, and blood pressure measures (millimeters of mercury $[\mathrm{mmHg}]$ ). Height was measured to the nearest 0.25 inch, and weight was measured to the nearest $0.25 \mathrm{lb}$ using a standard balance scale. Height and weight measurements were used to calculate a body-mass index for each subject using the Quetelet's equation $\left(\mathrm{kg} / \mathrm{m}^{2}\right)[29]$. Automated Welch Allyn ${ }^{\odot}$ sphygmomanometers were used to measure heart rate and systolic and diastolic blood pressures in each arm using a size-appropriate cuff. The measures were taken after the participant was seated quietly for 5-minutes with both feet flat on the floor and the back comfortably supported. An average heart rate and systolic and diastolic blood pressure was calculated for each subject based on two separate measures.

\section{Demographic and health behavior measures}

The NTHH study utilized standardized questions from the Behavioral Risk Factor Surveillance System to collect a selected number of demographic and health behavior information. Age was registered as a continuous variable (years). Race/ethnicity was self-reported and categorized as non-Hispanic white, non-Hispanic African American, Hispanic, and other. Education was measured by the question, "What is the highest grade or year of school that you completed?" Responses were then categorized as "less than high school", "high school graduate/GED", or "some 


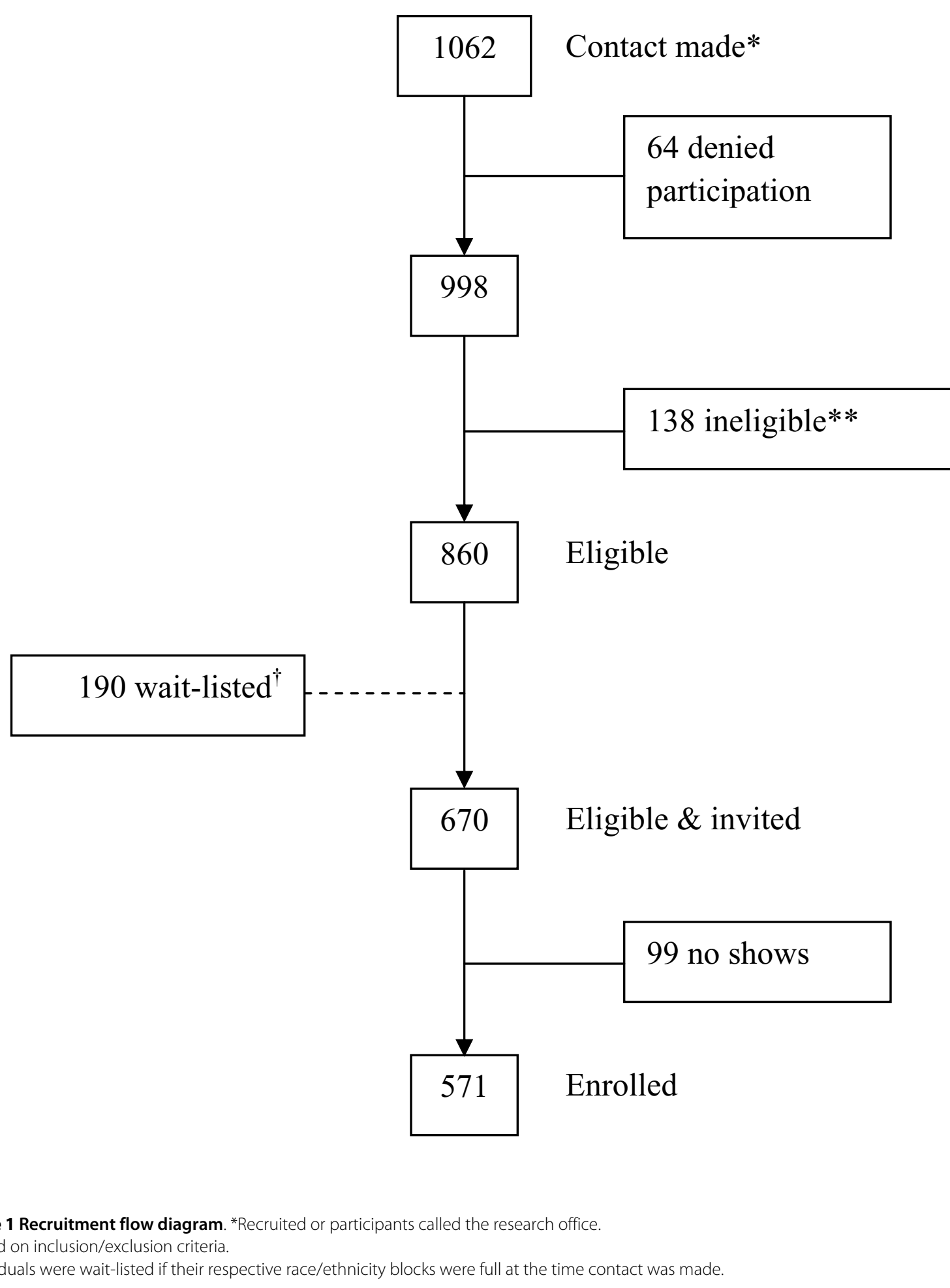

college or greater". Smoking status was assessed by asking, "Have you smoked at least 100 cigarettes in your lifetime?" Subjects were categorized as smokers if they responded "Yes".

\section{Physiologic and clinical measures}

The presence of coronary calcium was measured using a 16-slice MSCT scan and characterized as a dichotomous variable, consistent with previous studies $[6,28,30]$ : pres- 
ence of calcification (Agatston score (31) of greater than zero) or no calcification (Agatston score of zero). The MSCT took images every $3 \mathrm{~mm}$ from the carina to the base of the heart, and double inspiration was used to minimize breathing motion artifact on images. The participant had an electrocardiogram machine attached to correlate the heart rate with the images for the Vitrea software to calculate quantitative calcium scores. The total time in the scanner was 10-15 minutes, which was open with no contrast was given. Coronary artery calcification (CAC) quantification was reviewed and interpreted by a radiologist from Radiology Associates at the Center for Diagnostic Imaging at the University of North Texas Health Science Center who was blinded to participant characteristics.

Clinical factors included history of a first degree relative with heart disease, depression symptomatology, hypertension, diabetes, and lipid status. Fasting (8 hour) blood was collected for serum chemistries and analyzed using a commercial laboratory. History of a first degree relative with heart disease was categorized as yes or no. The Center for Epidemiologic Studies Depression Scale (CES-D) was used to measure depressive symptomatology (Cronbach $\alpha .85-.90)$ [32]. The CES-D measures current level of depressive symptomatology with emphasis on the affective component, depressed mood. The CES-D score was dichotomized into high depressive symptomatology (scores $\geq 17$ ) and low depressive symptomatology (score $<17$ ) based on previous research. Hypertension was considered present if the blood pressure was greater than or equal to $140 / 90 \mathrm{~mm} \mathrm{Hg}$ for systolic or diastolic pressure, the subject reported being diagnosed with hypertension, or the subject was taking antihypertensive medications. Diabetes was considered present if the fasting glucose level was greater than or equal to $126 \mathrm{mg} / \mathrm{dL}$, the subject reported being previously diagnosed with diabetes, or the subject was taking any diabetic medication. Hyperlipidemia was considered to be present if the participant had a LDL $\geq 160 \mathrm{mg} / \mathrm{dL}$, the participant reported being previously diagnosed with high cholesterol, or the participant was taking a lipid lowering medication.

\section{Self-reported racial discrimination and response to unfair treatment}

Self-reported racial discrimination (hereafter referred to as discrimination) and response to unfair treatment were measured using the Experience of Discrimination (EOD) instrument, which was validated in English and Spanish among a population of low-wage African American, Latino, and white workers (Cronbach's alpha $\geq 0.74, \mathrm{r}=$ 0.79) $[16,21,33]$. The EOD asks about ever experiencing discrimination, being prevented from doing something, being hassled or made to feel inferior because of race, ethnicity, or color in each of the following nine domains: at school; getting a job; at work; getting housing; getting medical care; getting service in a store or restaurant; getting credit, bank loans or a mortgage; on the street or in a public setting; or from the police or in the courts. The instrument was available to participants in English or Spanish. Discrimination was modeled as a dichotomous variable (no discrimination/any discrimination). Response to unfair treatment was measured by asking respondents, "If you have been treated unfairly, do you usually (1) talk to other people about it or (2) keep it to yourself?" Based on the instrument's guidelines, participants were categorized as passively responsive in which they internalized their action, or actively responsive in which they talked to others or did something about their experience.

\section{Statistical analyses}

All statistical analyses were performed using SPSS version 15.0[34]. Descriptive statistics are provided for all variables. Counts and frequencies are provided for categorical data, and means and standard deviations are provided for continuous variables. Independent sample $t$ tests and chi-square analyses were performed to test for differences in independent variables between participants with a CAC score of zero and those with a CAC score greater than zero (Table 1). Logistic regression was performed, and unadjusted and adjusted odds ratios and 95\% confidence intervals were calculated (Tables 2, 3, and 4). Statistical significance was assessed at the alpha $=0.05$ level.

The multiple logistic regression model assessed potential interaction for discrimination*response to unfair treatment and discrimination*race/ethnicity in the final model. Multicollinearity was assessed using Tolerance and Variation Inflation Factor (VIF) with all variables in the final model. No collinear relationships were identified. In addition, a sensitivity analysis was performed to assess whether depression symptomatology (i.e, CES-D) should be included in the final adjusted model. This was examined due to a lack of literature supporting the inclusion of depression symptomatology and the lack of significance in the unadjusted association between depression and CAC. A full regression model was composed with depression, and another model was composed without depression. The change in the -2 Log Likelihood was used to assess change in the fit of the model. Including depression symptomatology in the model decreased the -2 Log Likelihood. Missing data were imputed for discrimination and CES-D using the individual mean imputation method, which imputes a value based on how a subject responds to other questions. This method was chosen because of its simplicity and accuracy[35]. Missing data were not imputed for CAC scores (10.7\% missing), unfair treatment (1.6\% missing), gender $(0.4 \%$ missing $)$, educa- 
Table 1: Characteristics of North Texas Healthy Heart study participants by presence of coronary artery calcification-- Fort Worth, Texas, 2006-8 $(\mathrm{N}=510)$

\begin{tabular}{|c|c|c|c|}
\hline Variable & Any calcification, $\mathrm{n}(\%)$ & No calcification, $\mathbf{n}(\%)$ & p-value* \\
\hline Age, mean (SD) & $58.4(8.6)$ & $53.4(6.9)$ & $<.001$ \\
\hline Body mass index, mean (SD) & $32.0(7.0)$ & $30.4(6.0)$ & 0.01 \\
\hline Gender & & & $<.001$ \\
\hline Female & $90(28.4)$ & $227(71.6)$ & \\
\hline Men & $96(49.7)$ & $97(50.3)$ & \\
\hline Race/ethnicity & & & $<.001$ \\
\hline Non-Hispanic white & $71(50.0)$ & $71(50.0)$ & \\
\hline $\begin{array}{l}\text { Non-Hispanic African } \\
\text { American }\end{array}$ & $59(35.3)$ & $108(64.7)$ & \\
\hline Hispanic & $52(26.9)$ & $141(73.1)$ & \\
\hline Education & & & 0.39 \\
\hline Less than High school & $34(30.9)$ & $76(69.1)$ & \\
\hline High school graduate/GED & $39(37.5)$ & $65(62.5)$ & \\
\hline Some college or higher & $113(38.2)$ & $183(61.8)$ & \\
\hline $\begin{array}{l}\text { Smoked } \geq 100 \text { cigarettes in one's } \\
\text { life }\end{array}$ & & & 0.002 \\
\hline Yes & $95(44.4)$ & $119(55.6)$ & \\
\hline No & $89(30.8)$ & $200(69.2)$ & \\
\hline Diabetes Mellitus status & & & 0.005 \\
\hline Yes & $46(48.9)$ & $48(51.1)$ & \\
\hline No & $139(33.7)$ & $274(66.3)$ & \\
\hline Hypertension status & & & 0.004 \\
\hline Yes & $111(42.7)$ & $149(57.3)$ & \\
\hline No & $73(30.2)$ & $169(69.8)$ & \\
\hline Hyperlipidemia status & & & $<0.001$ \\
\hline Yes & $119(44.6)$ & $148(55.4)$ & \\
\hline No & $67(27.8)$ & $174(72.2)$ & \\
\hline $\begin{array}{l}\text { First degree relative with history } \\
\text { of coronary heart disease }\end{array}$ & & & 0.01 \\
\hline Yes & $106(41.9)$ & $147(58.1)$ & \\
\hline No & $76(31.3)$ & $167(68.7)$ & \\
\hline \multicolumn{4}{|l|}{ Depressive symptomatology } \\
\hline Low (CES-D score < 17) & $135(36.3)$ & $237(63.7)$ & \\
\hline High (CES-D score $\geq 17$ ) & $50(36.5)$ & $87(63.5)$ & \\
\hline
\end{tabular}


Table 1: Characteristics of North Texas Healthy Heart study participants by presence of coronary artery calcification-- Fort Worth, Texas, 2006-8 ( $=510)$ (Continued)

\begin{tabular}{lll}
\hline Response to unfair treatment & & 0.96 \\
$\begin{array}{ll}\text { Active } \\
\text { Passive }\end{array}$ & $123(37.0)$ & $209(63.0)$ \\
& $63(36.8)$ & $108(63.2)$ \\
\hline Experienced racial discrimination & & $227(64.5)$ \\
Yes & $125(35.5)$ & $97(61.4)$ \\
No & $61(38.6)$ & \\
\hline * P value corresponds to a two sided p value for t-tests for continuous variables and to chi square analyses for categorical variables.
\end{tabular}

* $\mathrm{P}$ value corresponds to a two sided $\mathrm{p}$ value for $\mathrm{t}$-tests for continuous variables and to chi square analyses for categorical variables.

tion ( $0.4 \%$ missing), smoking (1.8\% missing), diabetes (0.9\%), hypertension (2.1\%), hyperlipidemia (1.2\% missing), 1st degree family member with a history of heart disease (3.0\% missing), BMI (0.9\% missing), and age (0.5\% missing). There were no missing data for race/ethnicity, hypertension status, or diabetes status. This resulted in a final sample size of 510.

\section{Results}

Table 1 depicts the characteristics of the study population. One hundred eighty-six participants (32.6\%) had CAC present with scores ranging from 0 to 5098 Agatston $($ mean $=33$, standard deviation $=385$ ). Participants with $\mathrm{CAC}$ were older, male, white, had higher BMI, smoked, were diabetic, were hypertensive, had hyperlipidemia, and had a first degree relative with heart disease ( $\mathrm{p}<0.05$ for all variables) compared to participants without calcification. The prevalence of CAC was similar in different education level groups, those reporting high or low depressive symptomatology, and those actively or passively responding to unfair treatment. Among those reporting any discrimination, $46.8 \%$ were African American, $36.1 \%$ were Hispanic, and $17.1 \%$ were white. Discrimination was reported by $35.5 \%$ of participants with coronary calcification and by $38.6 \%$ of participants without calcification $(\mathrm{p}=0.50)$.

Results of the simple logistic regression model are shown in Table 2. Age and BMI were significantly associated with $\mathrm{CAC}$. Men were 2.5 times more likely to have CAC present compared to females, while African Americans and Hispanics were $45 \%$ and $63 \%$, respectively, less likely to have calcification compared to whites. Those who smoked, had diabetes, had hypertension, and had hyperlipidemia were more likely to have CAC present. Those with a $1^{\text {st }}$ degree relative with heart disease were approximately 1.5 times more likely to have CAC present. Education, depressive symptomatology, response to unfair treatment, and discrimination were not associated with CAC presence in these unadjusted models.

Race/ethnicity did not modify the relationship between discrimination and CAC. However, response to unfair treatment was found to significantly modify this relationship $(\mathrm{p}<0.001)$. Hence, the simple logistic regression model assessing the relationship between discrimination and $\mathrm{CAC}$ and the multiple logistic regression results were stratified by active and passive response to unfair treatment. The sensitivity analysis found depression symptomatology to decrease the fit of the model; hence, it was not included in the final adjusted model.

The simple logistic regression models for discrimination and CAC stratified by response to unfair treatment are presented in Table 3. Among those who passively responded, participants who had experienced discrimination were $25 \%$ more likely to have CAC present, although this was not statistically significant. Table 4 provides results for the adjusted logistic regression model. Among those who actively responded to unfair treatment, only increasing age, being male, and being Hispanic were significantly associated with the presence of CAC. Among those who passively responded to unfair treatment, increasing age, being male, being African American, and having a positive smoking status were significantly associated with CAC. Interestingly, the odds of having CAC present were approximately 3 times higher for those who experienced discrimination and passively responded to unfair treatment.

\section{Discussion}

This study of asymptomatic U.S. adults of different racial/ ethnic identity is the first to our knowledge to support the association between experiencing racial discrimination and an increased risk of coronary artery calcification, a marker for atherosclerosis. Our results contradict two other studies that have investigated the influence of racial discrimination or unfair treatment and subclinical atherosclerosis[28,36]. Both previous studies were restricted to women and both found that "everyday" discrimination was associated with subclinical coronary artery disease, measured by coronary calcium [28] and intima-media thickness,[36] although one reported the association only among African American females and the relationship was not statistically significant[36]. However, when both 
Table 2: Simple logistic regression models for coronary artery calcification -- Fort Worth, Texas, 2006-8 (N = 510)

\begin{tabular}{|c|c|c|}
\hline \multirow[b]{2}{*}{ Variable } & \multicolumn{2}{|c|}{ Any calcification } \\
\hline & $\mathbf{O R}^{*}$ & $95 \% \mathrm{Cl}^{*}$ \\
\hline Age & 1.09 & $1.06-1.11$ \\
\hline Body mass index & 1.04 & $1.01-1.07$ \\
\hline \multicolumn{3}{|l|}{ Gender } \\
\hline Female & $\ldots$ & $\ldots$ \\
\hline Men & 2.5 & $1.72-3.63$ \\
\hline \multicolumn{3}{|l|}{ Race/ethnicity } \\
\hline Non-Hispanic white & $\ldots$ & $\ldots$ \\
\hline Non-Hispanic African American & 0.55 & $0.35-0.86$ \\
\hline Hispanic & 0.37 & $0.23-0.58$ \\
\hline \multicolumn{3}{|l|}{ Education } \\
\hline Some college or higher & $\ldots$ & $\ldots$ \\
\hline Less than High school & 0.97 & $0.61-1.54$ \\
\hline High school graduate/GED & 0.72 & $0.45-1.16$ \\
\hline \multicolumn{3}{|l|}{ Smoked $\geq 100$ cigarettes in one's life } \\
\hline No & $\ldots$ & $\ldots$ \\
\hline Yes & 1.79 & $1.24-2.59$ \\
\hline \multicolumn{3}{|l|}{ Diabetes Mellitus status } \\
\hline No & $\ldots$ & $\ldots$ \\
\hline Yes & 1.89 & $1.20-2.97$ \\
\hline \multicolumn{3}{|l|}{ Hypertension status } \\
\hline No & $\ldots$ & $\ldots$ \\
\hline Yes & 1.73 & $1.19-2.49$ \\
\hline \multicolumn{3}{|l|}{ Hyperlipidemia status } \\
\hline No & $\ldots$ & $\ldots$ \\
\hline Yes & 2.09 & $1.44-3.03$ \\
\hline \multicolumn{3}{|l|}{$\begin{array}{l}\text { First degree relative with history of } \\
\text { coronary heart disease }\end{array}$} \\
\hline No & $\ldots$ & $\ldots$ \\
\hline Yes & 1.58 & $1.10-2.29$ \\
\hline \multicolumn{3}{|l|}{ Depressive symptomatology } \\
\hline Low (CES-D score < 17) & $\ldots$ & $\ldots$ \\
\hline High (CES-D score $\geq 17$ ) & 1.01 & $0.67-1.52$ \\
\hline
\end{tabular}


Table 2: Simple logistic regression models for coronary artery calcification -- Fort Worth, Texas, 2006-8 $(\mathrm{N}=\mathbf{5 1 0})$

\begin{tabular}{lcc}
\hline Response to unfair treatment & $\ldots$ & $\ldots$ \\
Active & 0.99 & $0.68-1.45$ \\
Passive & & $\ldots$ \\
\hline Experienced racial discrimination & & $\ldots .59-1.29$ \\
No & $\ldots .88$ & 0.29 \\
Yes & 0.88 & \\
\hline
\end{tabular}

${ }^{*} \mathrm{OR}=$ crude or unadjusted odds ratio, $\mathrm{Cl}=$ confidence interval

studies restricted this association to racial discrimination, the association was no longer apparent. The authors concluded that it is not the attribution of discrimination but the experience of chronic discrimination that influences CAC. Neither study assessed how response to unfair treatment modified the association between self-reported discrimination and sub-clinical atherosclerosis. Our findings parallel studies that have found discrimination to be associated with hypertension among those who passively respond, or internalize their response, to unfair treatment $[9,16,17]$. Hence, it appears that coping mechanisms, such as speaking out in response to racist events, mitigates the impact of racial discrimination on CAC. These results remained significant after adjusting for smoking status and BMI and suggest future interventional studies are needed that empower individuals and communities to address and respond to everyday inequalities.

Several potential mechanisms linking psychosocial stressors such as self-reported discrimination to the development of coronary artery calcified plaque have been proposed[10]. Inflammatory induction is a pathophysiologic process that may be mediated by psychosocial stressors. Emerging evidence indicates that CVD development may involve the release of cytokines such as interleukin- 6 and tumor necrosis factor $\alpha$ in an inflammatory response to epithelial damage stimulated by acute stressors[37]. Other possible mechanisms involve adverse health behaviors such as smoking, alcohol consumption, or poor diet in response to stress, which may contribute to risk,[38] although our results found several of these factors (i.e., smoking, and BMI) did not account for all of the adverse effect from racial discrimination.

The strengths of this study include the use of a validated instrument to measure discrimination and response to unfair treatment, the inclusion of multiracial/ ethnic asymptomatic adults, and the use of the MSCT scan to detect coronary calcification. However, our results are subject to a number of limitations. We attempted to measure cumulative discrimination by determining whether participants ever experienced racial discrimination, although it is possible that recall may not be complete. In addition, we did not measure discrimination attributable to other characteristics, such as gender. The cross-sectional nature of the study precludes any statements about causal associations.

Previous research has confirmed that the experience of discrimination or unfair treatment may act as a stressor and that the appraisal of stress may also be important to measure[18,20]. Future investigations should include measures of discrimination attributed to multiple characteristics, whether psychosocial factors are intermediate factors in this association, and the moderating effects of coping resources. Potential variation by gender, race, and level of educational attainment should also be incorporated. Finally, the measure of discrimination investigated should reflect a lifecourse perspective and account for

Table 3: Simple logistic regression model for the relationship between perceived racial discrimination and coronary artery calcification stratified by response to unfair racial treatment-- Fort Worth, Texas, 2006-8 ( $\mathbf{N}=\mathbf{5 1 0})$

\begin{tabular}{|c|c|c|c|c|}
\hline \multirow[b]{2}{*}{ Variable } & \multicolumn{2}{|c|}{ Active response to unfair treatment } & \multicolumn{2}{|c|}{ Passive response to unfair treatment } \\
\hline & $\mathbf{O R}^{*}$ & $95 \% \mathrm{Cl}^{*}$ & $\mathbf{O R}^{*}$ & $95 \% \mathrm{Cl}^{*}$ \\
\hline \multicolumn{5}{|c|}{$\begin{array}{l}\text { Experienced racial } \\
\text { discrimination }\end{array}$} \\
\hline No & $\ldots$ & $\ldots$ & $\ldots$ & $\ldots$ \\
\hline Yes & 0.69 & $0.42-1.15$ & 1.25 & $0.66-2.36$ \\
\hline
\end{tabular}

$\mathrm{OR}=$ crude or unadjusted odds ratio, $\mathrm{Cl}=$ confidence interval 
Table 4: Multiple logistic regression model for the relationship between perceived racial discrimination and coronary artery calcification stratified by response to unfair racial treatment-- Fort Worth, Texas, 2006-8 ( $N=510)$

\begin{tabular}{|c|c|c|c|c|}
\hline \multirow[b]{2}{*}{ Variable } & \multicolumn{2}{|c|}{ Active response to unfair treatment } & \multicolumn{2}{|c|}{ Passive response to unfair treatment } \\
\hline & OR* $^{*}$ & $95 \% \mathrm{Cl}^{*}$ & OR & $95 \% \mathrm{Cl}$ \\
\hline Age & 1.09 & $1.05-1.13$ & 1.1 & $1.04-1.16$ \\
\hline Body mass index & 1.03 & $0.99-1.08$ & 1.08 & $1.01-1.15$ \\
\hline \multicolumn{5}{|l|}{ Gender } \\
\hline Female & $\ldots$ & $\ldots$ & $\ldots$ & $\ldots$ \\
\hline Men & 3.4 & $1.96-5.88$ & 2.32 & $1.01-5.35$ \\
\hline \multicolumn{5}{|l|}{ Race/ethnicity } \\
\hline Non-Hispanic white & $\ldots$ & $\ldots$ & $\ldots$ & $\ldots$ \\
\hline $\begin{array}{l}\text { Non-Hispanic African } \\
\text { American }\end{array}$ & 0.64 & $0.31-1.32$ & 0.26 & $0.08-0.84$ \\
\hline Hispanic & 0.4 & $0.18-0.88$ & 0.49 & $0.15-1.55$ \\
\hline \multicolumn{5}{|l|}{ Education } \\
\hline Some college or higher & $\ldots$ & $\ldots$ & $\ldots$ & $\ldots$ \\
\hline Less than High school & 1.1 & $0.46-2.62$ & 0.33 & $0.10-1.06$ \\
\hline $\begin{array}{l}\text { High school graduate/ } \\
\text { GED }\end{array}$ & 1.23 & $0.62-2.44$ & 0.66 & $0.24-1.83$ \\
\hline \multicolumn{5}{|l|}{$\begin{array}{l}\text { Smoked } \geq 100 \text { cigarettes in } \\
\text { one's life }\end{array}$} \\
\hline No & $\ldots$ & $\ldots$ & $\ldots$ & $\ldots$ \\
\hline Yes & 1.27 & $0.74-2.19$ & 2.56 & $1.05-6.40$ \\
\hline \multicolumn{5}{|l|}{ Diabetes Mellitus status } \\
\hline No & $\ldots$ & $\ldots$ & $\ldots$ & $\ldots$ \\
\hline Yes & 1.91 & $0.94-3.89$ & 1.35 & $0.46-3.99$ \\
\hline \multicolumn{5}{|l|}{ Hypertension status } \\
\hline No & $\ldots$ & $\ldots$ & $\ldots$ & $\ldots$ \\
\hline Yes & 1.15 & $0.64-2.04$ & 1.13 & $0.48-2.68$ \\
\hline \multicolumn{5}{|l|}{ Hyperlipidemia status } \\
\hline No & $\ldots$ & $\ldots$ & $\ldots$ & $\ldots$ \\
\hline Yes & 1.64 & $0.95-2.83$ & 2.08 & $0.86-4.99$ \\
\hline \multicolumn{5}{|l|}{$\begin{array}{l}\text { First degree relative with } \\
\text { history of coronary heart } \\
\text { disease }\end{array}$} \\
\hline No & $\ldots$ & $\ldots$ & $\ldots$ & $\ldots$ \\
\hline Yes & 1.08 & $0.63-1.85$ & 0.95 & $0.40-2.23$ \\
\hline
\end{tabular}


Table 4: Multiple logistic regression model for the relationship between perceived racial discrimination and coronary artery calcification stratified by response to unfair racial treatment-- Fort Worth, Texas, 2006-8 $(\mathbf{N}=510)$ (Continued)

\begin{tabular}{|c|c|c|c|c|}
\hline \multicolumn{5}{|c|}{$\begin{array}{l}\text { Experienced racial } \\
\text { discrimination }\end{array}$} \\
\hline No & $\ldots$ & $\ldots$ & $\ldots$ & $\ldots$ \\
\hline Yes & 0.8 & $0.41-1.54$ & 2.95 & $1.19-7.32$ \\
\hline
\end{tabular}

* $\mathrm{OR}=$ adjusted odds ratio, $\mathrm{Cl}=$ confidence interval

cumulative experiences of unfair treatment that may influence the disease process since atherosclerosis develops over an extended period. Moreover, factors that may impact how self-reported and perceived racism is reported should be examined. Variations on how one interprets discrimination, whether due to social status, geographic variation, or personal history, may affect how discrimination is measured[39]. For example, one study was able to extract thoughts or reports of past racist events among its participants only when they went into in-depth discussions [40]. Also, types of racist experiences in society have changed over time from more overt events to more subtle ones [41], such as suppression in social status and its impact on home ownership or higher educational opportunities.

\section{Conclusions}

The persistence of racial disparities of CVD warrants investigations regarding the contribution of subjective experiences of discrimination and unfair treatment. Stress-related health literature has the potential to provide future direction. Focused efforts to elucidate whether racial and ethnic minorities differ in response to stressful situations, or types of stressful situations, may provide valuable insight for prevention and amelioration of CVD burden. Finally, because of the temporal lag between subclinical atherosclerosis and clinical coronary heart disease, the use of CAC as an endpoint should be emphasized in future epidemiologic studies of racial disparities in CVD.

\section{Abbreviations}

BMI: Body mass index; CAC: Coronary artery calcification; CES-D: Center for Epidemiologic Studies Depression Scale; CHD: Coronary heart disease; Cl: Confidence interval; CT: Computed tomography; CVD: Cardiovascular disease; EOD: Experiences of Discrimination instrument; $\mathrm{mmHg}$ : Millimeters of mercury; MSCT: Muli-slice computed tomography; NorTex: North Texas Primary Care Practice Based Research Network; NTHH: North Texas Healthy Heart study; ORs: Odds ratio

\section{Competing interests}

The authors declare that they have no competing interests.

\section{Authors' contributions}

RC conceived of the study, design and analyzed the data, and was the primary writer of the manuscript. KMC and KGF assisted in methodology of the study, assisted in data analyses, edited the manuscript. JC oversaw all labs analyses and methodology and edited the manuscript. AE oversaw daily study recruitment and execution of the project and edited the manuscript. CC, JV, RY, and
DS all recruited study participants and were involved in manuscript development and editing. All authors read and approved the final manuscript.

\section{Acknowledgements}

The authors are grateful for the assistance of Ana L. Chiapa, Mayra Rodriguez, Lorna Brooks and the Primary Care Research Institute staff of the University of North Texas Health Science Center. We also want to thank the clinicians of the North Texas Primary Care Research Network who helped recruit study participants. The project described was supported by Grant Number P20MD001633 from the National Center On Minority Health And Health Disparities and the $\mathrm{NIH}$ Loan Repayment Program. The content is solely the responsibility of the authors and does not necessarily represent the official views of the National Center On Minority Health and Health Disparities or the National Institutes of Health.

\section{Author Details}

1Department of Family Medicine, Primary Care Research Institute, Texas College of Osteopathic Medicine, University of North Texas Health Science Center, 3500 Camp Bowie Blvd, Fort Worth, TX, 76107, USA, ${ }^{2}$ Department of Epidemiology, School of Public Health, University of North Texas Health Science Center, 3500 Camp Bowie Blvd, Fort Worth, TX, 76107, USA

3Department of Integrative Physiology, Graduate School of Biomedical Sciences, University of North Texas Health Science Center, 3500 Camp Bowie Blvd, Fort Worth, TX, 76107, USA, ${ }^{2}$ Department of Family Medicine, John Peter Smith Health Network, 1500 South Main St, Fort Worth, TX, 76104, USA and

5Family Medicine Private Practice, HEB Family Care Clinic, Euless, TX, 76039, USA

Received: 28 August 2009 Accepted: 27 May 2010

Published: 27 May 2010

\section{References}

1. Lloyd-Jones D, Adams R, Carnethon M, De SG, Ferguson TB, Flegal K, et al:: Heart disease and stroke statistics--2009 update: a report from the American Heart Association Statistics Committee and Stroke Statistics Subcommittee. Circulation 2009, 119(3):480-486.

2. Konety SH, Vaughan Sarrazin MS, Rosenthal GE: Patient hospital differences underlying racial variation in outcomes after coronary artery bypass graft surgery. Circulation 2005, 111(10):1210-1216.

3. Benjamin EJ, Jessup M, Flack JM, Krumholz HM, Liu K, Nadkarni VM, Rhoades DA, Rodriguez BL, Scott RP, Taylor MP, Velazquez EJ, Winkleby MA: Discovering the full spectrum of cardiovascular disease: Minority Health Summit 2003: report of the Outcomes Writing Group. Circulation 2005, 111(10):e124-e133.

4. Everson-Rose SA, Lewis TT: Psychosocial factors and cardiovascular diseases. Annu Rev Public Health 2005, 26:469-500.

5. Krantz DS, McCeney MK: Effects of psychological and social factors on organic disease: a critical assessment of research on coronary heart disease. Annu Rev Psychol 2002, 53:341-369.

6. Kop WJ, Berman DS, Gransar H, Wong ND, Miranda-Peats R, White MD, Shin M, Bruce M, Krantz DS, Rozanski A: Social network and coronary artery calcification in asymptomatic individuals. Psychosom Med 2005 67(3):343-352.

7. Clark R, Anderson NB, Clark VR, Williams DR: Racism as a stressor for African Americans. A biopsychosocial model. Am Psychol 1999, 54(10):805-816

8. Pascoe EA, Smart RL: Perceived discrimination and health: a metaanalytic review. Psychol Bull 2009, 135(4):531-554.

9. Williams DR, Mohammed SA: Discrimination racial disparities in health evidence and needed research. J Behav Med 2009, 32(1):20-47. 
10. Brondolo E, Brady N: Racism as a psychosocial stressor. In Handbook of Stress Science New York: Springer; 2009.

11. Williams DR, Gonzalez HM, Williams S, Mohammed SA, Moomal H, Stein $D J$ : Perceived discrimination, race and health in South Africa. Soc Sci Med 2008, 67(3):441-452.

12. Sellers SL, Bonham V, Neighbors HW, Amell JW: Effects of racial discrimination and health behaviors on mental and physical health of middle-class African American men. Health Educ Behav 2009, 36(1):31-44.

13. Chae DH, Takeuchi DT, Barbeau EM, Bennett GG, Lindsey J, Krieger N: Unfair treatment, racial/ethnic discrimination, ethnic identification, and smoking among Asian Americans in the National Latino and Asian American Study. Am J Public Health 2008, 98(3):485-492.

14. Mays VM, Cochran SD, Barnes NW: Race race-based discrimination, and health outcomes among African Americans. Annu Rev Psychol 2007, 58:201-225.

15. The Vulnerable Atherosclerotic Plaque: Strategies for Diagnosis and Management. Malden, MA: Blackwell; 2007.

16. Krieger N: Racial gender discrimination: risk factors for high blood pressure? Soc Sci Med 1990, 30(12):1273-1281

17. Brondolo E, Brady Ver HN, Pencille M, Beatty D, Contrada RJ: Coping with racism: a selective review of the literature and a theoretical and methodological critique. J Behav Med 2009, 32(1):64-88.

18. Williams DR, Neighbors HW, Jackson JS: Racial/ethnic discrimination and health: findings from community studies. Am J Public Health 2003, 93(2):200-208

19. Krieger N, Chen JT, Waterman PD, Hartman C, Stoddard AM, Quinn MM, Sorensen G, Barbeau EM: The inverse hazard law: blood pressure, sexual harassment, racial discrimination, workplace abuse and occupational exposures in US low-income black, white and Latino workers. Soc Sci Med 2008, 67(12):1970-1981.

20. Paradies Y: A systematic review of empirical research on self-reported racism and health. Int J Epidemio/ 2006, 35(4):888-901.

21. Krieger N, Smith K, Naishadham D, Hartman C, Barbeau EM: Experiences of discrimination: validity and reliability of a self-report measure for population health research on racism and health. Soc Sci Med 2005, 61(7):1576-1596.

22. Friedman EM, Williams DR, Singer BH, Ryff CD: Chronic discrimination predicts higher circulating levels of E-selectin in a national sample: the MIDUS study. Brain Behav Immun 2009, 23(5):684-692.

23. Greenland P, LaBree L, Azen SP, Doherty TM, Detrano RC: Coronary artery calcium score combined with Framingham score for risk prediction in asymptomatic individuals. JAMA 2004, 291(2):210-215.

24. Haberl R, Becker A, Leber A, Knez A, Becker C, Lang C, Bruning R, Reiser M, Steinbeck G: Correlation of coronary calcification and angiographically documented stenoses in patients with suspected coronary artery disease: results of 1,764 patients. J Am Coll Cardiol 2001, 37(2):451-457

25. Pletcher MJ, Tice JA, Pignone M: Use of coronary calcification scores to predict coronary heart disease. JAMA 2004, 291(15):1831-1832.

26. Detrano R, Guerci AD, Carr JJ, Bild DE, Burke G, Folsom AR, Liu K, Shea S, Szklo M, Bluemke DA, O'Leary DH, Tracy R, Watson K, Wong ND, Kronmal RA: Coronary calcium as a predictor of coronary events in four racial or ethnic groups. N Engl J Med 2008, 358(13):1336-1345.

27. Raggi P, Taylor A, Fayad Z, O'Leary D, Nissen S, Rader D, Shaw LJ: Atherosclerotic plaque imaging: contemporary role in preventive cardiology. Arch Intern Med 2005, 165(20):2345-2353.

28. Lewis TT, Everson-Rose SA, Powell LH, Matthews KA, Brown C, Karavolos K, Sutton-Tyrrell K, Jacobs E, Wesley D: Chronic exposure to everyday discrimination and coronary artery calcification in African-American women: the SWAN Heart Study. Psychosom Med 2006, 68(3):362-368

29. Keys A, Fidanza F, Karvonen MJ, Kimura N, Taylor HL: Indices of relative weight and obesity. J Chronic Dis 1972, 25(6):329-343.

30. Budoff MJ, Yang TP, Shavelle RM, Lamont DH, Brundage BH: Ethnic differences in coronary atherosclerosis. J Am Coll Cardiol 2002, 39(3):408-412.

31. Agatston AS, Janowitz WR, Hildner FJ, Zusmer NR, Viamonte M Jr, Detrano R: Quantification of coronary artery calcium using ultrafast computed tomography. J Am Coll Cardiol 1990, 15(4):827-832

32. Radloff LS: A self-report depression scale for research in the genera population. Applied Psychological Measurement 1977, 1(3):385-401.
33. Krieger N, Sidney S: Racial discrimination and blood pressure: the CARDIA Study of young black and white adults. Am J Public Health 1996, 86(10):1370-1378.

34. SPSS: Chicago. IL; 2005.

35. Shrive FM, Stuart H, Quan H, Ghali WA: Dealing with missing data in a multi-question depression scale: a comparison of imputation methods. BMC Med Res Methodol 2006, 6:57.

36. Troxel WM, Matthews KA, Bromberger JT, Sutton-Tyrrell K: Chronic stress burden, discrimination, and subclinical carotid artery disease in African American and Caucasian women. Health Psychol 2003, 22(3):300-309.

37. Steptoe A, Willemsen G, Owen N, Flower L, Mohamed-Ali V: Acute mental stress elicits delayed increases in circulating inflammatory cytokine levels. Clin Sci (Lond) 2001, 101(2):185-192.

38. Rozanski A, Blumenthal JA, Kaplan J: Impact of psychological factors on the pathogenesis of cardiovascular disease and implications for therapy. Circulation 1999, 99(16):2192-2217.

39. Karlsen S, Nazroo JY: Relation between racial discrimination, social class, and health among ethnic minority groups. Am J Public Health 2002, 92(4):624-631.

40. Parker H, Botha JL, Haslam C: "Racism" as a variable in health research can it be measureed? J Epidemiol Community Health 1994, 48:522.

41. Dovidio JF, Gaertner SL: Aversive racism and selection decisions: 1989 and 1999. Psychol Sci 2000, 11(4):315-319.

\section{Pre-publication history}

The pre-publication history for this paper can be accessed here: http://www.biomedcentral.com/1471-2458/10/285/prepub

doi: 10.1186/1471-2458-10-285

Cite this article as: Cardarelli et al., Self-reported racial discrimination, response to unfair treatment, and coronary calcification in asymptomatic adults - the North Texas Healthy Heart study BMC Public Health 2010, 10:285

\section{Submit your next manuscript to BioMed Centra and take full advantage of:}

- Convenient online submission

- Thorough peer review

- No space constraints or color figure charges

- Immediate publication on acceptance

- Inclusion in PubMed, CAS, Scopus and Google Scholar

- Research which is freely available for redistribution 